\title{
Engineering and sustainability performance of self-compacting palm oil mill incinerated waste concrete
}

\author{
Jegathish Kanadasan, Hashim Abdul Razak* \\ StrucHMRS Group, Department of Civil Engineering, Faculty of Engineering, University of Malaya, 50603 Kuala Lumpur, Malaysia
}

A R T I C L E I N F O

\section{Article history:}

Received 7 April 2014

Received in revised form

14 July 2014

Accepted 1 November 2014

Available online 7 November 2014

\section{Keywords:}

Self-compacting concrete

Cleaner environment

\begin{abstract}
A B S T R A C T
The different stages in the processing of palm oil generate various types of waste by-products, which have to be disposed of appropriately for a cleaner environment and to reduce pollution. In this study, palm oil clinker (POC), one of the by-products of the palm oil mill, was utilized in the production of selfcompacting concrete (SCC). SCC has diverse types of structural application due to its own enhanced selfconsolidating behaviour. The proportioning of the mixes was based on particle packing, which integrates both aggregate packing and void volume for a mix of aggregates. Combinations of POC and natural aggregate were studied at various substitution levels ranging from $0 \%$ to $100 \%$ for both fresh and hardened properties. In addition, a few of the results were integrated into sustainability components to evaluate the effectiveness of the concrete both economically and environmentally. It was found that POC aggregate require three times lower energy consumption for preparation compared to conventional aggregate. Overall, $\mathrm{POC}$ incorporation showed enhanced structural efficiency with a significant reduction in cost and energy usage. Furthermore, the sustainability of the construction industry can be conserved with the introduction of POC as an alternative source for concreting work.
\end{abstract}

() 2014 Elsevier Ltd. All rights reserved.

\section{Introduction}

Waste by-products originating from various manufacturing processes need proper management to ensure a cleaner and nonpolluted environment. The agricultural industry in Malaysia has been contributing substantially to the economy of the country over the past few decades. Substantial areas of land have been planted with commercial plants, such as oil palm, paddy, rubber, cocoa, sugar cane, tea and coconut. The conversion of these plants into useful goods during the processing stages produces huge amount of waste, which require a good disposal system to prevent any environmental pollution. These wastes vary from waste grains, wastewater, ash, fibres and solid chunks. The oil palm industry in Malaysia has grown rapidly over the past few decades and has become one of the major exporters of palm oil goods to many parts of the world. In 2012, it was reported that the total production of crude palm oil was more than 18.7 million tonnes (Halimah et al., 2013). At the end of the palm oil processing stages, various types and forms of waste by-products are obtained, which need serious attention and appropriate disposal methods. The solid wastes

\footnotetext{
* Corresponding author. Tel.: +60 3 79675233; fax: +60 379675381.

E-mail addresses: jegathish@siswa.um.edu.myand (J. Kanadasan), hashim@um.
} edu.my (H. Abdul Razak).

http://dx.doi.org/10.1016/j.jclepro.2014.11.002

0959-6526/O 2014 Elsevier Ltd. All rights reserved. generated include oil palm shell (OPS), fibres, empty fruit bunches (EFB), palm oil clinker (POC) and palm oil fuel ash (POFA). In addition, palm oil mill effluent (POME), which is the other major waste in the form of wastewater, could have disastrous effects on the environment if not managed appropriately. Some of these waste by-products have a high potential for being converted into a useful energy source to supplement additional needs. Yusoff (2006) reported that the abundant supply of oil palm waste in Malaysia has a high potential for being utilized as an alternative renewable energy source.

POC was utilized in this study for the production of selfcompacting concrete (SCC) for concrete construction. Palm oil clinker (POC) which is obtained as a final by-product from the incineration process of oil palm shell and mesocarp fibre, is usually landfilled in the plantation areas or used as a cover for potholes on the roads leading to the estates. The POC is obtained in large chunks from the mill and is much lighter in nature. Crushing it into suitable sizes provides an ideal alternative source of aggregate. Besides being utilised as an aggregate, POC has also been ground into fine powder to be used as a binder material to enhance the selfconsolidating behaviour. The utilization of self-compacting concrete (SCC) worldwide has increased over the last few decades. SCC provides numerous advantages not only to the overall construction industry, but also in respect of health and the environment. High 
quality structures and good surface finishing are some of the key components of using SCC in the industry. Furthermore, there is a significant reduction in noise pollution and labour strain. From an engineering perspective, the utilization of POC in SCC will produce an ideal combination between lightweight concrete and selfcompacting concrete. Hence, this self-compacting lightweight concrete (SCLC) will help to decrease the overall mass of the concrete matrix and avoid unnecessary loading to optimize the transfer of load.

Researchers report that $50 \%$ of carbon dioxide emissions originate from the built environment; thus, resulting in a significant rise in green-house gas (GHG) emissions, globally (Khasreen et al., 2009). By taking into account the problems relating to environmental pollution and emissions, utilizing POC in concrete would be a smart choice to ensure a clean atmosphere. It would help to preserve the depleting natural aggregates and pave the way for proper consumption. In this study, the utilization of POC was maximized in SCC whereby POC aggregates were used to replace natural aggregates while $\mathrm{POC}$ powder was incorporated as an additional binder material. Their fresh and hardened properties were evaluated to understand the effect of replacing these waste materials in concrete. Fresh SCC properties were evaluated thoroughly to ensure that they meet all the requirements stipulated by EFNARC (2005); while the hardened properties were subjected to non-destructive tests, which included ultrasonic pulse velocity (UPV) and electrical resistivity. The structural efficiency concept was explored by combining the strength and density components of the concretes to gain a good comparison platform at various substitution levels. Sustainability components were analysed in terms of carbon emission, cost factor and energy usage. The combined evaluation between engineering properties and sustainability aspects provides the positive effects of using POC in the concrete.

\section{Previous studies}

Over the years, research on the utilization of waste materials in concrete has been on the rise to reduce the problems relating to environmental pollution. In the construction industry, these waste materials are commonly used as aggregate, powder materials replacing cement and admixtures. The incorporation of black rice husk ash (BRHA) in concrete as a replacement to cement at $0 \%-40 \%$ has the capability of reducing the autogenous shrinkage (Chatveera and Lertwattanaruk, 2011). Studies have found that the utilization of treated effluent from the heavy industry as mixing water has elevated the compressive strength compared to potable water (Noruzman et al., 2012). Generally, the addition of waste plastic reduces the concrete strength, which could be due to the lower adhesive behaviour between the plastic and the cement paste (Ismail and Al-Hashmi, 2008). The utilization of used engine oil as an air entraining agent has approximately similar compressive strength characteristics to that of the control mix besides reducing the flexural strength by $21 \%$, tensile strength by $17 \%$ and modulus of elasticity by 6\% (Hamad et al., 2003). Ling and Poon (2012) reported that the drying shrinkage of crushed funnel glass (CFG) and treated funnel glass (TFG) included in heavyweight barite concrete (HWBC) was much lower compared to those in the control mix. The lower water absorption characteristics of these materials could be the reason behind this situation. The results were also similar to those obtained by Kou and Poon (2009) in that lower drying shrinkage than the control mix was observed using recycled glass in a proportion of $45 \%$ as a substitute for the fine aggregate.

Although the addition of waste foundry sand generally reduces the compressive strength and tensile strength, at $10 \%$ replacement they showed almost similar characteristics to that of the control specimens (Guney et al., 2010). Researchers have found from their study that using recycled ceramic aggregate has improved both compressive strength and splitting tensile strength, whereby at 28 days for $25 \%$ replacement level, an increase of $12 \%-25 \%$ was noticed when compared to the control specimen (Medina et al., 2012). Both waste paper sludge ash (WSA) and ground granulated blast furnace slag (GGBS) have good potential to act as binders in concrete without cement (Gailius and Laurikietyté, 2003). The flexural strength of self-compacting glass concrete (SCGC) incorporating $20 \%$ and $30 \%$ of glass sand content was higher when compared to the control concrete at 90 days (Wang and Huang, 2010). When steel chips were utilized as a replacement to sand, the compressive strength increased as the amount of this waste material increased (Alwaeli and Nadziakiewicz, 2012). The usage of glass aggregate (GA) exhibited an almost similar carbonation depth at 91 days compared to that of the reference concrete (de Castro and de Brito, 2013). The electrical resistivity of the SCC using waste tyre rubber powder increased as the substitution level rose (Yung et al., 2013). Lightweight concrete incorporating aggregate made up of sewage sludge waste glass powder showed good hardened properties whereby they were able to produce $73 \%$ of the strength compared to that of the control concrete and had good surface resistivity values (Tuan et al., 2013).

The incorporation of crumb rubber (CR) showed an improvement in terms of fracture energy by 3.5-5.4 times compared to the ordinary concrete (Grinys et al., 2013). Studies on the usage of brass by-products in concrete found that the ultrasonic pulse velocity (UPV) and compressive strength values increased when cement was replaced by between 5\% and 15\% (Zubaidi et al., 2013). In addition, the utilization of lightweight aggregate produced using municipal solid waste incinerator (MSWI) fly ash and reservoir sediment in self-consolidating lightweight concrete (SCLWC) showed good concrete strength with satisfactory UPV and electrical resistivity values (Hwang et al., 2012). The replacement of crushed glass and imploded glass between $10 \%$ and $20 \%$ improved the concrete resistance to chloride ion ingression (Cassar and Camilleri, 2012). Kinuthia et al. (2009) reported that the inclusion of colliery spoil with sand and aggregate could produce almost $42 \%$ of the compressive strength compared to normal concrete. Researchers reported that the fracture energy was elevated by $194 \%$ when recycled fine crumb rubber was substituted with $10 \%$ sand, while at $20 \%$ replacement the fracture energy was increased by $268 \%$ (AlTayeb et al., 2013). Furthermore, using SCC for construction purposes compared to normal concrete has plenty of advantages, both in the casting process, as well as in the output of the concrete. Among others, these advantages include reduced labour needs, lower noise pollution and shorter construction period. Rwamamara and Simonsson (2012) found that SCC has various benefits in terms of the less stressful working conditions due to the fewer physical activities compared to normal vibrated concrete.

\section{Material and methods}

\subsection{Materials}

POC coarse, POC fine, gravel and sand were used in this study at various replacement levels. Table 1 tabulates the physical characteristics of the aggregates utilized in this study. The cement utilized in this study was ordinary Portland cement (Type I). In addition, POC powder was incorporated into the mix as a binder material to provide the required paste volume. Table 2 lists the chemical compositions of these binder materials. The superplasticiser used for this work was polycaboxylate based. A large POC chunk collected from the mill is shown in Fig. 1, while the coarse and fine POC, after being prepared in the laboratory, is shown in Fig. 2. 
Table 1

Physical characteristics of aggregates.

\begin{tabular}{lllllll}
\hline Aggregate & $\begin{array}{l}\text { Aggregate } \\
\text { size }(\mathrm{mm})\end{array}$ & Specific gravity & $\begin{array}{l}\text { Moisture } \\
\text { content }(\%)\end{array}$ & $\begin{array}{l}\text { Water } \\
\text { absorption (\%) }\end{array}$ & $\begin{array}{l}\text { Aggregate crushing } \\
\text { value (\%) }\end{array}$ & $\begin{array}{l}\text { Aggregate crushing } \\
\text { value (ten per cent fines) }\end{array}$ \\
\hline Fine POC & $<5$ & 1.97 & $0.5 \pm 0.25$ & $10 \pm 5$ & - & - \\
Coarse POC & $5-14$ & 1.73 & $1 \pm 0.5$ & $3 \pm 2$ & 56.44 & 16.99 \\
Sand & $<5$ & 2.60 & 0.07 & 1.59 & - & - \\
Gravel & $5-14$ & 2.65 & 0.27 & 0.55 & 18.22 & - \\
\hline
\end{tabular}

\subsection{Mix design development}

Taking into consideration the utilization of POC aggregate, which contain a substantial amount of pores and are irregular in shape, the mix proportioning technique was modified. Particle packing (PP) was introduced, which provides the aggregate packing level as well as the void volume (Kanadasan and Razak, 2014). Through this method, the required amount of paste to coat and give extra lubrication to the POC aggregate can be determined. The extra paste volume was provided to the mix design system to enhance the self-compacting behaviour of the concrete. The excess paste effect will elevate the self-consolidating behaviour in terms of the passing ability and flowability of the POC aggregate besides improving some of the other concrete properties. An important consideration was to ensure that a low cement content was used throughout the study to reduce the carbon emissions that cause environmental pollution. Therefore, the extra paste volume required by the mix was supplied through the addition of $\mathrm{POC}$ powder instead of using cement. The study involved the investigation of various replacement levels of POC ranging from $0 \%$ to $100 \%$, which were designed based on the PP concept. The mix proportions are presented in Table 3. Through this, not only can the utilization of palm oil waste be maximized, but also the sustainability of the construction industry can be preserved.

\section{Results and discussion}

\subsection{Slump flow}

The relationships among the slump flow, $\mathrm{POC}$ replacement ratio and paste volume are depicted in Fig. 3. Studies of the fresh properties were carried out to ensure that the SCC meets the requirements stipulated by EFNARC (2005). The shear stress of a mix greatly influences the flowability. An increasing pattern of slump flow can be observed as the POC substitution level rises. This could be explained by a few major factors. One of them is the higher particle packing for POC 0 mix, which induces higher shear stress across the concrete matrix. The decreasing trend of PP values from

Table 2

Chemical composition of POC powder and cement.

\begin{tabular}{lcc}
\hline Oxides & POC powder & Cement \\
\hline $\mathrm{Na}_{2} \mathrm{O}$ & - & 0.24 \\
$\mathrm{Mn}_{2} \mathrm{O}_{3}$ & - & 0.12 \\
$\mathrm{TiO}_{2}$ & 0.29 & 0.12 \\
$\mathrm{~K}_{2} \mathrm{O}$ & 15.10 & 0.17 \\
$\mathrm{P}_{2} \mathrm{O}_{5}$ & 3.47 & 0.07 \\
$\mathrm{MgO}_{\mathrm{Al}} \mathrm{O}_{3}$ & 3.30 & 3.13 \\
$\mathrm{Fe}_{2} \mathrm{O}_{3}$ & 3.89 & 5.37 \\
$\mathrm{SO}_{3}$ & 6.93 & 2.94 \\
$\mathrm{SiO}_{2}$ & 0.39 & 2.61 \\
$\mathrm{CaO}$ & 59.90 & 20.29 \\
$\mathrm{Others}$ & 6.37 & 64.00 \\
Loss on ignition & 0.36 & 0.94 \\
& 1.89 & 1.40 \\
\hline
\end{tabular}

POC 0 to POC 100 greatly influences the stresses that exist within the vicinity of the concrete phase to give a larger slump diameter. Concurrently, a lower lubrication effect for highly packed aggregate combination also increases the friction between the paste and the aggregate to elevate the shear stress. This leads to the lower rolling capability of the natural aggregate to produce a much smaller slump diameter compared to other mixes. On the other hand, POC 100 with the lowest PP values corresponding to the highest paste volume provides a good coating and lubrication effect on and between the aggregate to give the highest slump diameter. Secondly, the much less denser POC particles, be it POC aggregate or POC powder, will lower the stress effect. This will ease the movement or flow of the overall concrete structure as the weight reduces substantially. As noticed from Fig. 3, the POC 100 mix produced the highest slump flow. The slump flow results were within class SF 2 under the EFNARC range (EFNARC, 2005).

\section{V-funnel}

The relationships among the V-funnel flow time, POC replacement ratio and paste volume are depicted in Fig. 4. The volume of paste plays a vital role in affecting the viscosity and flowability of SCC. Despite having a small variation in the V-funnel flow time between POC 100 and POC 75, the time of flow generally decreases with the escalating $\mathrm{POC}$ replacement ratio. The increment in paste volume with regards to the higher POC replacement level helps to coat and improve the flow process allowing for a greater flowability rate. The coating of paste helps to enhance the rolling capability of the porous POC aggregate. Furthermore, the much lower specific gravity of both the POC aggregate and POC powder tends to reduce the overall mass of the concrete resulting in a greater flow rate. The lower paste volume for POC 0 , which has the highest packing effect, reduces the lubrication effect between the aggregate; hence, resulting in a highly viscous mix with a longer flow time. This increases the tendency of the fresh concrete to have high friction internally between the aggregate and the paste phase leading to higher viscosity.

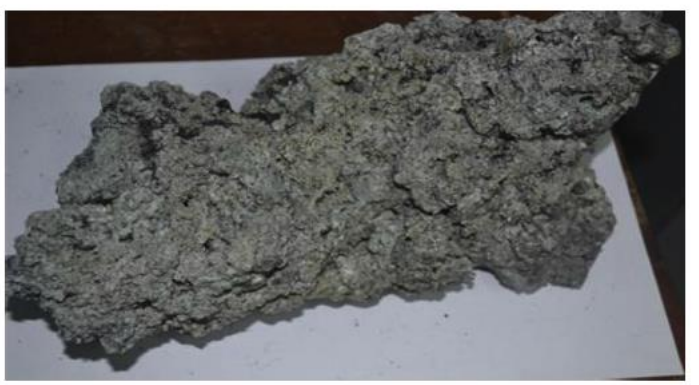

Fig. 1. A large POC chunk. 


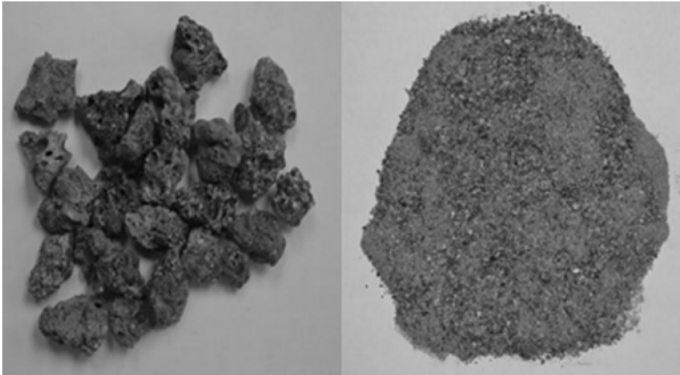

Fig. 2. POC coarse and $P O C$ fine.

\subsection{T500 time}

Fig. 5 shows the effect of the POC replacement ratio and paste volume on the $T_{500}$ time. The viscous state of the mix and the characteristics of the aggregate combination used play an important role in exhibiting the flow time. The availability of a high amount of lightweight aggregate with increased paste volume reduces the overall weight of the concrete skeleton to produce a much shorter $T_{500}$ time for POC 100 . Generally, as the replacement level rises, a reduction in time observed confirms that POC does affect the concrete matrix density. While, on the other hand, POC 0 , which comprises gravel and sand, produced a longer $T_{500}$. This could be explained by the heavier matrix of the overall concrete and highly viscous condition of the fresh mix. A lesser lubrication effect between particles corresponding to a lower paste volume results in a congested environment leading to a slower compactability effect. As observed from the figure also, all the mixes produced a $T_{500}$ time of more than $2 \mathrm{~s}$.

\subsection{L-box}

The flow between the reinforcement is particularly evaluated in this test. The passing ability of the SCC was improved with the introduction of excess paste. The POC aggregate, which is porous in nature, was tailored to the SCC mix design through this technique. A part of the paste helps to coat the aggregate to provide better transportation effects through the paste phase and elevate the passing ability performance of the concrete. The coated aggregate travels much easier with the high paste to the given concrete region. All five mixes studied in this research showed a passing ratio of 1.0 conforming to class PA 2 passing ability EFNARC (2005).

\subsection{Density}

Fig. 6 shows the relationship between the density, POC replacement ratio and reduction in concrete density. A lower unit

Table 3

Mix proportion for POC SCC.

\begin{tabular}{llllll}
\hline Components & \multicolumn{5}{l}{ POC replacement ratio } \\
\cline { 2 - 6 } & 0 & 25 & 50 & 75 & 100 \\
\hline Gravel & 644 & 459 & 289 & 136 & - \\
Sand & 947 & 675 & 425 & 200 & - \\
POC Coarse & - & 100 & 189 & 266 & 333 \\
POC Fine & - & 171 & 322 & 455 & 568 \\
Cement & 450 & 450 & 450 & 450 & 450 \\
POC Powder & 155 & 199 & 247 & 294 & 341 \\
Water & 175 & 188 & 202 & 216 & 230 \\
SP (\%) & 1.10 & 0.95 & 0.80 & 0.65 & 0.50 \\
\hline
\end{tabular}

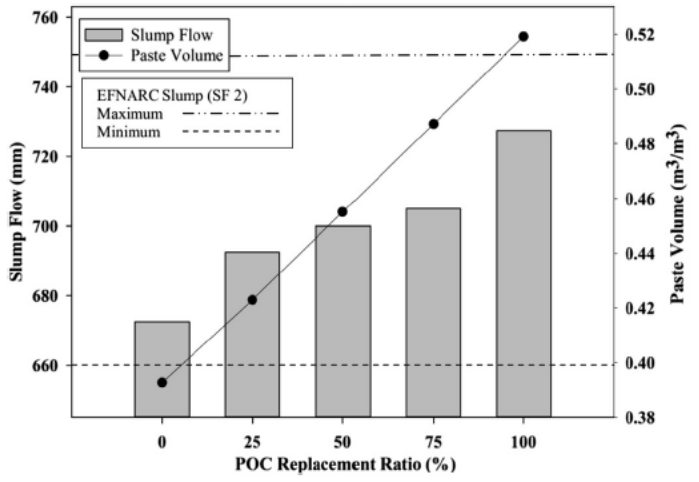

Fig. 3. Relationship between the slump flow, POC replacement ratio and paste volume,

weight coupled with the porous nature of the POC aggregate directly results in a lower mass per volume of POC SCC. A full replacement of $\mathrm{POC}$ produces concrete with a density less than $2000 \mathrm{~kg} / \mathrm{m}^{3}$, which is approximately $16 \%$ lower than POC $0 . \mathrm{A}$ combination of natural aggregate and POC aggregate at 50\% and $75 \%$ also showed a notable decrease in the density of the concrete, which is much closer to the lightweight concrete region. Another vital consideration is the capability of POC concrete to bear the load with reduced density. The structural efficiency concept was introduced and evaluated with regards to both the density and compressive strength achieved. This will be highlighted in the next section. It is observed from the relationship between the density and compressive strength that the full replacement of POC has the ability to take up a significant amount of load with respect to POC 0 . 4.6. Compressive strength

Fig. 7 shows the effect of the POC replacement ratio on the compressive strength of SCC at 3 and 28 days. The test was carried out according to BS EN 12390-3 (2009). A decreasing strength value can be observed as the POC incorporation rose. The strength of the aggregate, which is indirectly represented by the aggregate crushing value (ACV) greatly influences the maximum load it can take. As per the information in Table 1, a higher crushing value of around $68 \%$ is noticed for the POC coarse aggregate relative to the

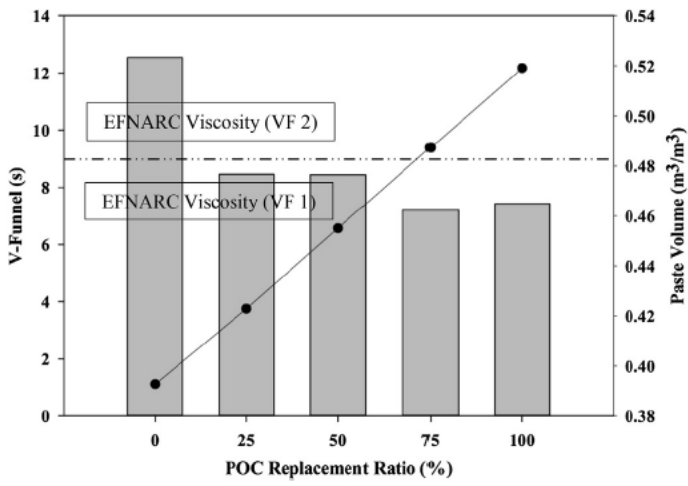

Fig. 4. Relationship between the V-funnel, POC replacement ratio and paste volume. 


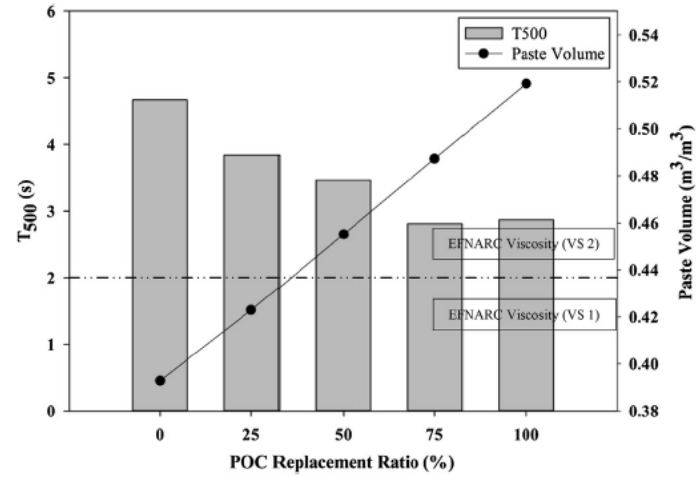

Fig. 5. Relationship between the $T_{500}$ time, POC replacement ratio and paste volume

gravel. The loading capacity of POC is much lower, which may be caused by the large number of voids both externally and internally. In addition, the packing level of the aggregate combination may also have played a vital role in exhibiting the strength. The highly packed structure of POC 0 shows good strength achievement compared to other mixes substituted with POC. The results are similar to those obtained by Kanadasan and Razak (2014). Another reason for this can be explained through the shape and reduced interlocking effect between the POC aggregate. Lower particle packing values were achieved when the POC aggregate was included. It is observed that the strength capacity reduces as the density diminishes. However, an important consideration is the effectiveness of the POC mix to sustain the load when compared to the relative mix with only natural aggregate.

\subsection{Ultrasonic pulse velocity (UPV)}

Fig. 8 shows the progression of UPV values for different POC replacement ratios at 3 and 28 days. Researchers have rated UPV values between $3660 \mathrm{~m} / \mathrm{s}$ and $4575 \mathrm{~m} / \mathrm{s}$ as concrete with good quality (Hwang et al., 2012). Within three days of evaluation, all the samples surpassed the minimum threshold value for 'good' quality concrete. However, a decreasing pattern of UPV was observed as the POC incorporation increased. This is closely related to the

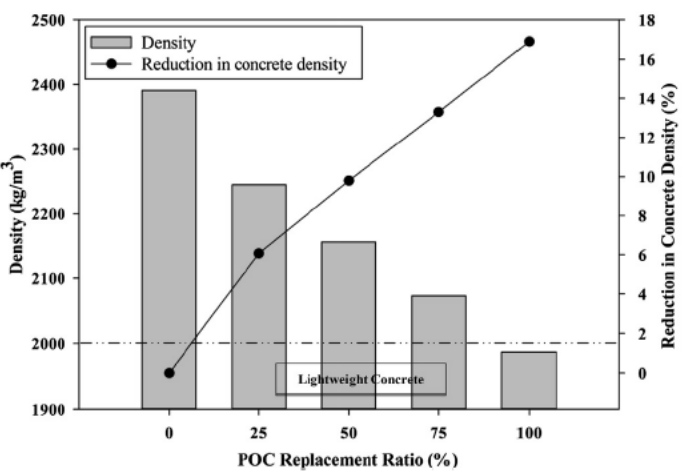

Fig. 6. Relationship between the density, POC replacement ratio and reduction in concrete density.

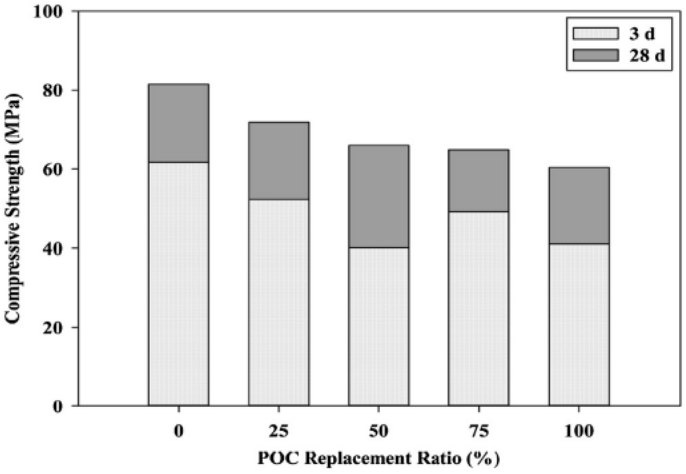

Fig. 7. Effect of POC replacement ratio on the compressive strength of SCC.

structure of the POC aggregate and resulting PP. Concurrently, the PP of the aggregate combination can be indirectly evaluated through this test. The drop in velocity could be due to the characteristics of the POC aggregate itself, which is highly porous and irregular in shape, and unable to form a good bond with other aggregate and the paste, for the formation of a highly packed concrete structure. Voids that are created as a result of the lack of an interlocking effect lead to a lower pulse travel rate. In this study, fully replaced POC concrete can be regarded as 'good' quality as the pulse rate lies above $3800 \mathrm{~m} / \mathrm{s}$. The incorporation of lightweight aggregate generally produces lower UPV values than the control specimens, which is also similar to the trend for electrical resistivity (Hwang et al., 2012). Based on the overall results, POC SCC can be classified as good quality concrete. Fig. 9 shows the relationship between the UPV test and the compressive strength at 28 days. A drop in the strength with respect to the increasing POC replacement ratio can be clearly observed to have a good correlation with the UPV values. Again, the rising porous condition and lack of good bond formation between the POC aggregate play a vital role in lowering the UPV and strength properties.

\subsection{Structural efficiency}

Fig. 10 shows the relationship between the structural efficiency and the POC replacement ratio. As the strength of concrete becomes

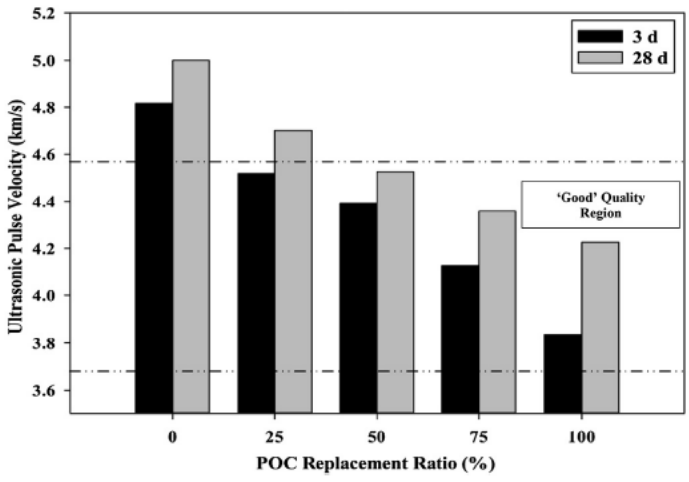

Fig. 8. Relationship between ultrasonic pulse velocity (UPV) and POC replacement ratio. 


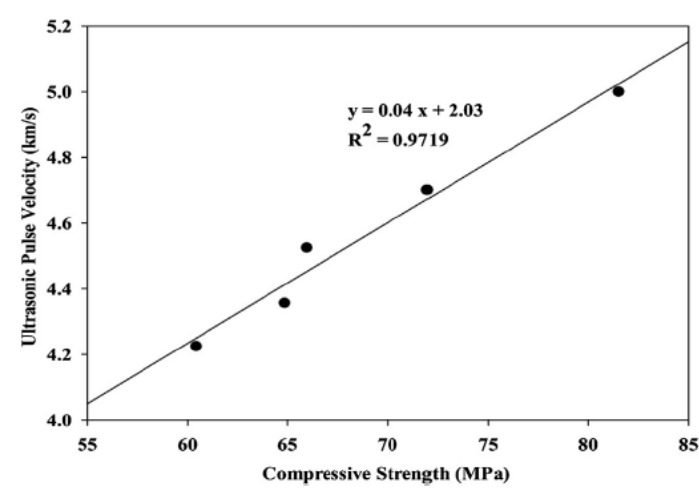

Fig. 9. Relationship between ultra-sonic pulse velocity (UPV) and compressive strength at 28 days.

lower with respect to the density for lightweight concrete, a different method is required for appropriate evaluation. Comparisons between the strength of lightweight concrete are usually distinguished through the structural efficiency concept (Choi et al., 2006). As there is a good correlation between the compressive strength and the reduction in density, the structural efficiency concept will provide a good insight into the performance of POC lightweight concrete. In comparing the control concrete to the concrete with POC, generally, there is a significant reduction. This may be due to the capability of the lightweight aggregate itself to withstand a high load due to the shape and considerable porosity. Fig. 11 shows the effect of PP on structural efficiency. There is an acceptable correlation between PP and structural efficiency at $R^{2}$ 0.7306 . The achievement of higher PP values corresponds to the good interlocking effect between the aggregate and indicates fewer voids within the aggregate paste skeleton. This, in turn, helps to maximize the strength properties. Fig. 12 shows the relationship between the structural efficiency and UPV. As previously discussed, UPV values serve as an indicator of the PP for a given concrete matrix. Hence, higher UPV values denote a good bond between the aggregate and the paste phase to enhance the properties of the hardened concrete.

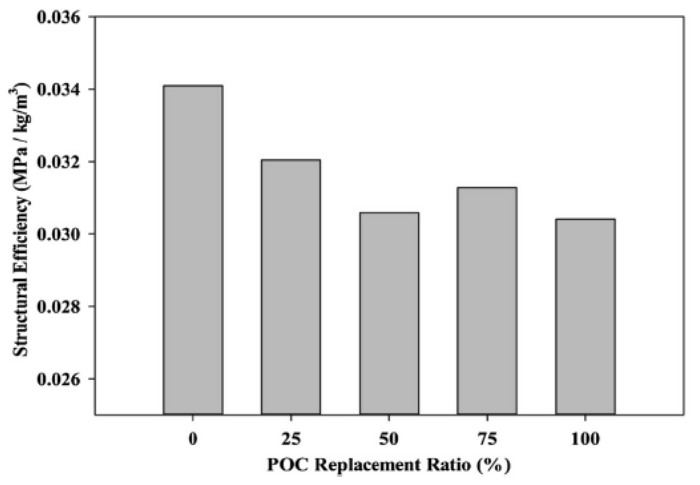

Fig. 10. Relationship between structural efficiency and POC replacement ratio

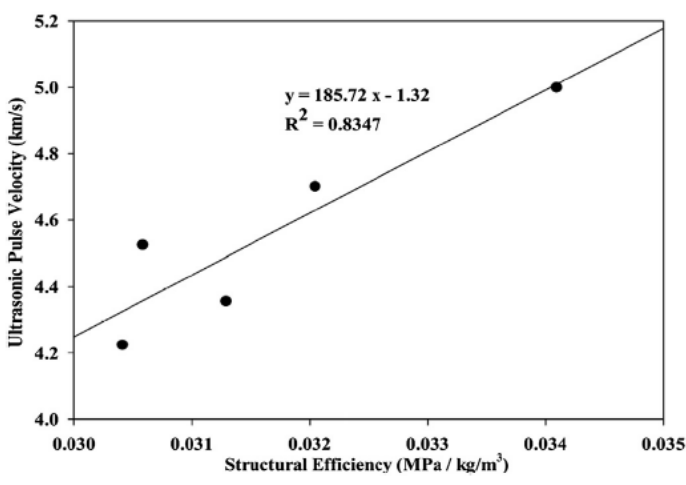

Fig. 11. Relationship between ultra-sonic pulse velocity (UPV) and structural efficiency.

\subsection{Electrical resistivity}

The electrical resistivity test was carried out to understand the resistance of POC SCC against corrosion. Fig. 13 shows the plot of electrical resistivity against the POC replacement ratio at 3 and 28 days. It is observed that at various replacement rates, the resistivity was well above $23 \mathrm{k} \Omega \mathrm{cm}$ at 28 days. An interesting finding was that for the sample incorporating $75 \%$ of POC, whereby the resistivity readings were higher than the control specimens although the initial value was much lower. Analysing the overall outcome, the comparable resistivity values between the control specimens and the samples fully replaced with POC show acceptable durability properties. Looking at the overall resistivity outcome, the variation between all the five mixes was relatively small. Researchers agree that a minimum value of electrical resistivity of $8.5 \mathrm{k} \Omega \mathrm{cm}$ is vital to prevent corrosion (Hope et al., 1985; Kayali and Zhu, 2005). Previous studies incorporating waste materials also showed good electrical resistance properties (Wang and Huang, 2010).

\section{Cost and sustainability}

\subsection{Engineering economic index}

Table 4 indicates the approximate prices of various material used in conventional concrete and POC SCC. In addition, Table 5

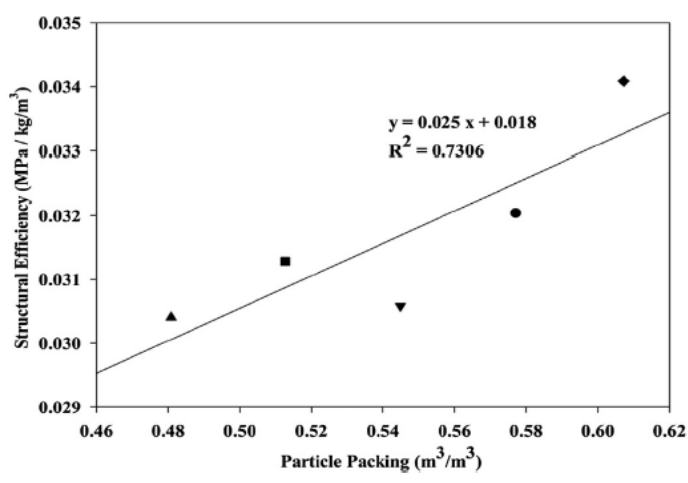

Fig. 12. Relationship between structural efficiency and particle packing 


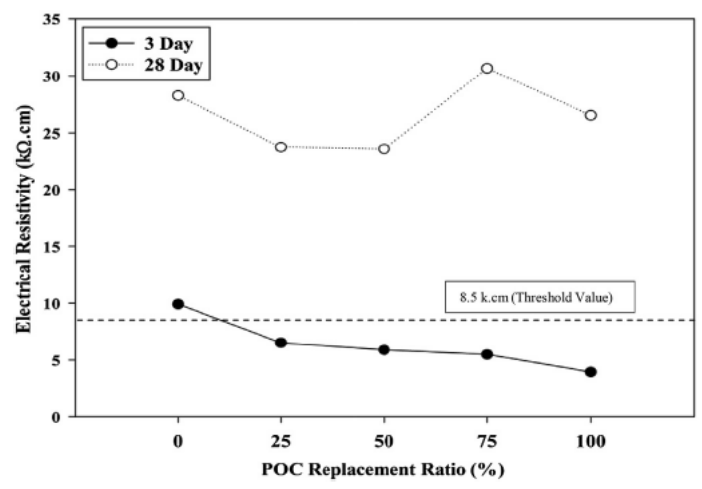

Fig. 13. Relationship between electrical resistivity and POC replacement ratio.

shows the comparison of mix proportion, for two conventional SCC (Su et al., 2001; Valcuende et al., 2012) and two POC mixes (from this study) with their total cost. A clear reduction in cost for POC 100 can be observed compared to all the other mixes. The utilization of POC 100 significantly reduced the cost of concrete by $31.54 \%$ when compared to control concrete in this study. The significant reduction in cost coupled with the lightweight characteristic could provide a positive contribution to the environment as well as to the economic point of view. In view of structural efficiency, POC 100 mixes showed approximately comparable values relative to that of the control concrete. Taking into account the normalization of the structural efficiency with regards to the cost factor (Engineering Economic Index, ECI), usage of POC showed greater values compared to that of the control concrete. The relationships between the cost of concrete, POC replacement ratio and engineering economic index are depicted in Fig. 14. An escalating trend can be observed as the POC replacement level rises. POC 100 produced the highest engineering economic values compared to the other mixes. This was mainly due to the lowest cost factor involvement as POC are collected cheaply. Furthermore, the satisfactory structural efficiency also promotes good engineering economic values for the POC mixes.

Thus, on a large scale or for mass concreting works, the appropriate application of $\mathrm{POC}$ incorporated concrete would greatly help in cost cutting measures in the construction industry. A 'zero waste' concept, which was adopted by using POC powder instead of other types of mineral admixture as replacement for the aggregate, also allowed for the maximum utilization of POC. Cost saving measures can also be implemented through the utilization of POC powder to

Table 4

Cost of materials by weight $(\mathrm{RM} / \mathrm{kg})$.

\begin{tabular}{lc}
\hline Materials & Cost $(\mathrm{RM} / \mathrm{kg})$ \\
\hline Cement & 0.440 \\
Gravel & 0.055 \\
Sand & 0.080 \\
POC coarse & 0.020 \\
POC fine & 0.020 \\
Fly ash & 0.150 \\
Ground granulated blast-furnace slag (GGBS) & 0.030 \\
POC powder & 0.020 \\
Limestone powder (LP) & 0.400 \\
Superplasticizer (SP) & 15.28 \\
Metakaolin & 2.420 \\
Silica fume & 2.420 \\
\hline
\end{tabular}

Table 5

Mix design comparison for conventional SCC and POC SCC.

\begin{tabular}{|c|c|c|c|c|}
\hline Material $\left(\mathrm{kg} / \mathrm{m}^{3}\right)$ & $\begin{array}{l}\text { Conventional } \\
\text { (Su et al. 2001) }\end{array}$ & $\begin{array}{l}\text { Conventional } \\
\text { (Valcuende } \\
\text { et al. 2012) }\end{array}$ & $\begin{array}{l}\text { POC } 0 \\
\text { (this study) }\end{array}$ & $\begin{array}{l}\text { POC } 100 \\
\text { (this study) }\end{array}$ \\
\hline Cement & 350 & 300 & 450 & 450 \\
\hline Gravel & 706 & 733.6 & 644 & - \\
\hline Sand & 912 & 1072.7 & 947 & - \\
\hline POC coarse & - & - & - & 333 \\
\hline POC fine & - & - & - & 568 \\
\hline POC powder & - & - & 155 & 341 \\
\hline $\begin{array}{l}\text { Ground granulated } \\
\text { blast-furnace } \\
\text { slag (GGBS) }\end{array}$ & 61 & - & - & - \\
\hline Fly ash & 142 & - & - & - \\
\hline $\begin{array}{l}\text { Limestone } \\
\quad \text { powder (LP) }\end{array}$ & - & 125 & - & - \\
\hline $\begin{array}{l}\text { Superplasticizer (SP) } \\
\text { Metakaolin } \\
\text { Silica fume }\end{array}$ & 8.80 & 5.70 & 6.65 & 3.96 \\
\hline Total Cost $\left(\mathrm{RM} / \mathrm{m}^{3}\right)$ & 423.38 & 395.26 & 413.89 & 283.35 \\
\hline Total Cost $\left(\mathrm{USD}^{\mathrm{a}} / \mathrm{m}^{3}\right)$ & 128.69 & 120.14 & 125.80 & 86.12 \\
\hline
\end{tabular}

a 1 USD = RM 3.29 (As of 17 February 2014)

further enhance the concrete properties as additional binder materials. Sustainability in terms of the substitution of the natural materials with waste or environmentally friendly resources and energy savings has been the focus in the construction industry. Certain parts of the industry, which may need to implement cost savings and green products, may benefit by adopting POC. In addition to saving the currently utilized resources, use of these abundantly available waste materials will help to reduce the potentially dangerous effects to the environment.

\subsection{Energy efficiency}

Another important consideration has to be given to the difference in the aggregate crushing value (ACV) for POC aggregate. Based on Table 1 , the crushing energy required to crush the aggregate can be directly related to energy consumption. The production of POC aggregate will be three times higher compared to gravel for the same crushing energy used. A highly porous nature with numerous voids within the internal structure of the aggregate reduces the amount of load to break apart the holding force. On the other hand, gravel, which is much stiffer and solid, needs a huge amount of energy to separate it. Hence, it can be concluded that a

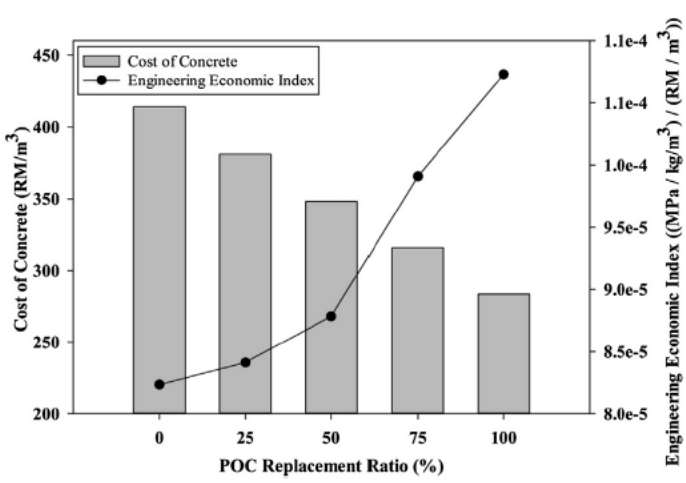

Fig. 14. Relationship between the cost of concrete, POC replacement ratio and engineering economic index.

\section{Link to Full-Text Articles :}

